\title{
THE RECOVERY ICE STREAM: SYNERGY OF SATELLITE AND AIRBORNE REMOTE SENSING FOR FLOW DYNAMICS
}

\author{
Dana Floricioiu ${ }^{l}$, Wael Abdel Jaber ${ }^{1,}$ Michael Baessler ${ }^{1}$, Veit Helm ${ }^{2}$ and Kenneth Jezek ${ }^{3}$ \\ ${ }^{1}$ DLR IMF, Oberpfaffenhofen, Germany \\ ${ }^{2}$ Alfred Wegener Institute (AWI), Bremerhaven, Germany \\ ${ }^{3}$ Byrd Polar Research Center, Ohio State University, Columbus OH, USA
}

\begin{abstract}
The Recovery Ice Stream with its large catchment basin plays an important role in discharging ice from East Antarctica into the Weddell Sea through the Filchner Ice Shelf. Its scientific interest is also linked to the discovery that the ice flow is influenced by the discharge of several subglacial lakes, which could trigger a faster flow due to reduced friction on the glacier bed.

We analyzed surface elevations of the Recovery Glacier system in Antarctica derived from time series of TanDEM-X data with focus on location of subglacial lakes. The absolute calibration of the TanDEM-X DEMs was performed using airborne laser altimetry datasets from NASA's Operation Icebridge ATM and AWI's Polar 6. In addition the grounding line position for the neighbouring Slessor, Bailey and Recovery glaciers was estimated through DInSAR with TerraSAR-X data acquired in 2014 and 2015.
\end{abstract}

Index Terms - TanDEM-X, DEM differencing, elevation change, Recovery ice stream.

\section{INTRODUCTION}

The Recovery Ice Stream (previously called Recovery Glacier) is Antarctica's longest dynamic ice flow feature, extending $\sim 1000 \mathrm{~km}$ into the interior of the East Antarctic Ice Sheet [1]. It drains a large area of Dronning Maud land ( $8 \%$ of the entire Antarctic ice sheet area) and provides $58 \%$ of the ice flux into the Filchner Ice Shelf. Under the main trunk of the lower Recovery ice stream ten active lakes were detected and four more large lakes were identified further upstream close to the onset area of fast flow [2].

The Recovery Ice Stream is situated at latitude above $80^{\circ} \mathrm{S}$ where a limited amount of high resolution satellite data is available. SAR data acquisition can occur only in left looking mode. Recovery Ice Stream is far from major research bases and the number of field expeditions has been limited so far. In austral summer 2014 AWI initiated the Recovery Ice Stream and Lakes (RECISL) campaign with overflights of Polar 6 aircraft equipped with laser altimeter for the surface topography and ground penetrating radar for the underlying bed.

In this paper we give particular attention to areas in the vicinity of the mentioned subglacial lakes. We compute surface elevations from bistatic TanDEM-X data and we complement these elevations with measurements of the Airborne Topographic Mapper (ATM) optical LiDAR during Operation IceBridge (OIB) in 2011 and 2012 and Polar 6 in January 2014.

Monostatic repeat pass TerraSAR-X data are used to derive the grounding line of Recovery Ice Stream and two neighboring glaciers and compare with previously derived grounding lines.

\section{DIGITAL ELEVATION MODEL FROM TANDEM-X DATA}

The TanDEM-X mission covered operationally Antarctica in left looking mode with two dedicated campaigns during the Austral winter of 2013 and 2014. A third bistatic data set was acquired over a selected coverage in October 2015 within the science dedicated phase of the mission. Since the operational processing of these data is still ongoing we processed internally Raw DEMs with the ITP processor [2] over an area around $110000 \mathrm{~km}^{2}$ (Fig. 1).

The TanDEM-X DEM better quality in respect to the older GLOBE DEM can be observed in Fig. 2. The comparison highlights the lack of spatial detail of the GLOBE DEM and potential vast disagreement between the two elevations as well.

The absolute calibration of the TanDEM-X Raw DEM elevations was performed using airborne laser altimetry datasets. Difficulties arise because of the lack of stable terrain and due to the penetration of the radar signal into ice and snow. The absolute accuracy of the TanDEM-X DEMs is around of $\pm 2 \mathrm{~m}$. We used data from the Airborne Topographic Mapper (ATM) flown aboard the NASA DC-8 aircraft during NASA's Operation IceBridge in 2011 and 2012 and data from Polar 6 laser altimeter acquired in January 2014. The altimetry flight lines at different 
locations over Recovery glacier main trunk are used in the present study are shown in Fig. 1.

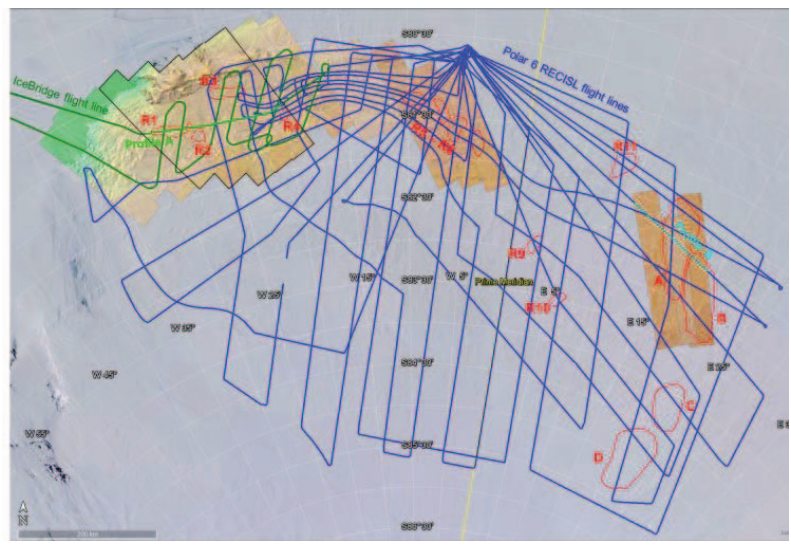

Fig. 1 Spatial coverage of the TanDEM-X DEM. Flight line of NASA's operation IceBridge of 18.10.2012 (dark green) and the section used for profile A (light green) in Fig. 3. Flight lines of AWI's RECISL flight campaign in January 2014 (blue) and the section used for profile B (cyan). The contour of the subglacial lakes are marked in red.

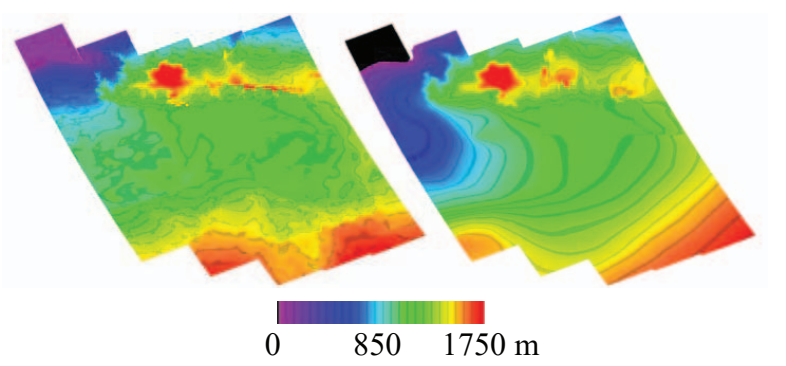

(a)

(b)

Fig. 2 Comparison between the TanDEM-X DEM (a) and the previously available GLOBE DEM (b). The imaged area is marked by a black contour in Fig. 1 .

The TanDEM-X interferometric elevations were compared to the laser altimeter measurements along the flight lines of the two aircrafts. The topography measured by the three instruments has a very similar pattern. Profile A (Fig. 3) highlights a strong dependence between elevation bias and the SAR backscattering coefficient $\sigma^{0}$. This suggests a relationship between TanDEM-X elevations and the variable scattering phase center position which is due to the influence of the SAR signal penetration in ice and snow.

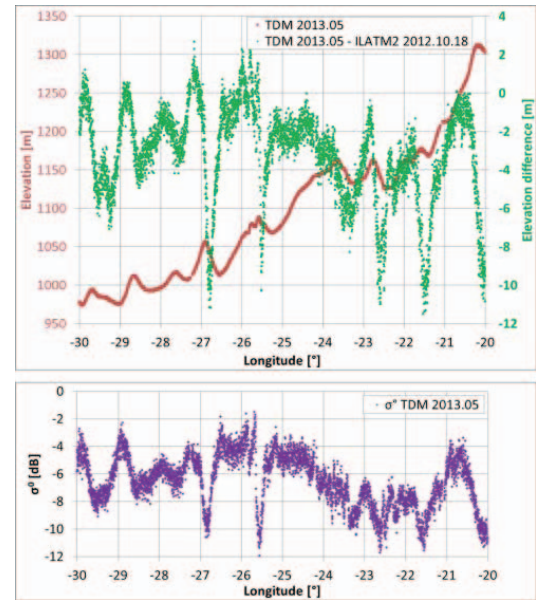

Fig. 3 Profile A of elevation difference between the TanDEM-X DEM and the ATM laser altimeter (green). Red: the TanDEM-X elevation profile. Magenta: the backscattering coefficient $\sigma^{0}$ of the TanDEM-X active channel.

\section{GROUNDING LINE POSITION WITH TERRASAR-X}

The location of the transition where the ice resting on bedrock detaches and becomes a floating ice shelf is a critical parameter needed for calculations of the ice sheet mass budget, as well as for modeling ice ocean interactions, ice sheet dynamics, subglacial melt and oceanic tides.

The InSAR double differencing method (DInSAR) has been applied for locating the vertical tidal deformation of the ice sheet. The deformation of the grounding zone appears in the double difference interferogram as a dense fringe belt which represents height changes due to ocean tides and air pressure differences between the SAR acquisitions. The upper limit of the tidal flexure was detected and mapped (blue and red lines) (Fig. 4).

The differences between the 2009 Radarsat- 2 and the TerraSAR-X based grounding line positions may be due to several factors, one of them could be the ocean tides itself. Depending on the subsurface topography minor height changes can cause a significant change in the location of the grounding line. 


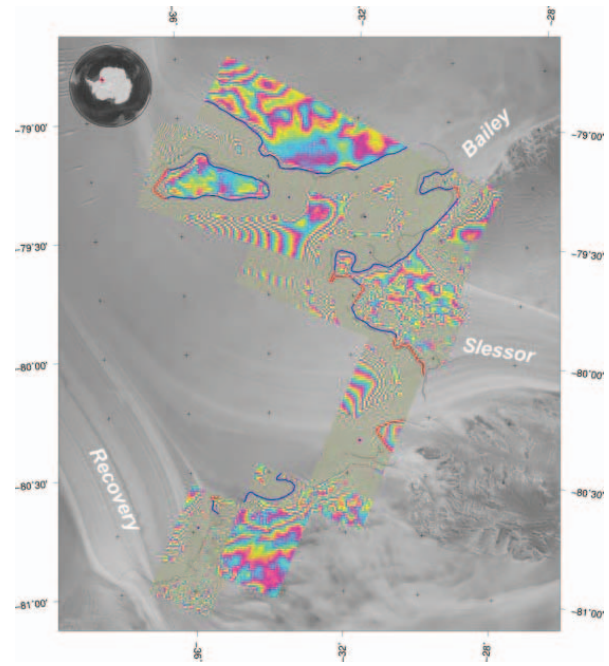

Fig. 4 Grounding line position for the Slessor, Bailey and Recovery glaciers estimated with TerraSAR-X data (blue and red lines). Grey line: the InSAR grounding line published at NSIDC [4].

\section{CONCLUSIONS AND OUTLOOK}

The high resolution DEM generated from TanDEM-X data from 2013 and 2014 offers an additional set of measurements to older elevation measurements. A detailed comparison of the SAR and laser altimetry data sets may be used to determine the penetration depth of Xband in ice. The TanDEM-X based Raw DEMs show a very detailed view of the topography in this poorly explored region in the interior of Antarctica. Our processing will be extended with the 2015 data set with the aim to detect possible subglacial lake activity of the Recovery Ice Stream. Due to the high vertical accuracy of the TanDEM-X DEMs this may be a promising time series to measure ice subsidence due to lake discharge.

Differential interferometry (DInSAR) was successfully applied on TerraSAR-X data to determine the position of the grounding line of the Recovery, Slessor and Bailey glaciers. Our work demonstrates the potential of TerraSAR-X data to complement Radarsat-2 based grounding lines at high latitudes with limited availability of SAR satellite data.

\section{REFERENCES}

[1] K. C. Jezek, K. Farness, R. Carande, X. Wu und N. Labelle-Hamer, „RADARSAT 1 Synthetic Aperture Observations of Antarctica: Modified Antarctic mapping Mission 2000,“ Radio Science, Bd. 38, Nr. 4.

[2] H. A. Fricker, S. P. Carter, R. E. Bell und T. Scambos, „Active lakes of Recovery Ice Stream, East Antarctica: a bedrock-controlled subglacial hydrological system,“ Journal of Glaciology, Bd. 60, 2014.

[3] C. Rossi, F. Rodriguez Gonzalez, T. Fritz, N. YagueMartinez und M. Eineder, „TanDEM-X calibrated Raw DEM generation," ISPRS Journal of Photogrammetry and Remote Sensing, Bd. 73, pp. 12 20, 2012.

[4] E. Rignot, J. Mouginot und B. Scheuchl, „Antarctic Grounding Line Mapping from Differential Satellite Radar Interferometry," Geophysical research Letters, Bd. 38, 2011.

\section{Acknowledgements}

Research supported by the Helmholtz Alliance project Remote Sensing and Earth System Dynamics. TanDEM-X data were provided within science proposal XTI_GLAC7035, TerraSAR-X data through proposal HYD 2059 . Additional data were obtained from NASA's Operation IceBridge. 